\title{
A Prospective Study on inappropriate Drug utilization in Geriatric Patients at A Tertiary Care Teaching Hospital
}

\author{
Pradeep Battula*1, Thandlam Muneeswar Reddy ${ }^{2}$, Thammisetty Durga Prasad ${ }^{2}$, Ranganayakulu Diviti ${ }^{3}$ \\ 1Department of Pharmacy Practice, Sri Padmavathi School of Pharmacy, Tiruchanoor, Tirupati, Andhra Pradesh, INDIA. \\ 2Department of General Medicine,Sri Venkateswara Medical College,Tirupati, Andhra Pradesh, INDIA. \\ ${ }^{3}$ Department of Pharmacology, Sri Padmavathi School of Pharmacy, Tiruchanoor, Tirupati, Andhra Pradesh, INDIA.
}

\begin{abstract}
Background: Prescribing to the older people is challenging. Pharmacokinetics and pharmacodynamic changes, chronic diseases, polypharmacy prescribing, potentially inappropriate medication (PIMs) prescribing, medication errors, adverse drug reactions, drug interactions, inappropriate prescribing or suboptimal prescribing are causes for challenge. It may lead to non-adherence, increase morbidity, length of hospitalization, poor quality of life, and finally death may occur. Method: A Prospective observational study was conducted in General Medicine department, for a period of 6 months. Patients of either gender who are above 65 years of age in general medicine in-patient ward with or without co-morbidities were included in the study; we excluded seriously ill and patients unable to communicate and Patients unwilling to participate in the study. Results: Total 140 geriatrics patients were admitted. In this study we observed that almost all prescriptions were with polypharmacy. PIMs observed from Beers criteria (17) and less in PRISCUS list (10). From both the lists 4 PIMs observed as same medications. Totally in 140 patients, 101 patients prescriptions were free from the PIMs, rest of the all potentially inappropriate prescriptions (PIPs). Conclusion: Inappropriate prescribing in geriatric patients is highly prevalent.
\end{abstract}

Key words: Geriatrics, Potentially Inappropriate Medications, Beers list, PRISCUS list, NLEM list, WHO list.

\section{INTRODUCTION}

The age 65 and above is considered as geriatrics, studying on geriatrics is called gerontology. ${ }^{1,2}$ The issues frequently raised regarding the geriatrics include - frailty, over use of medication (polypharmacy), inappropriate prescribing, under use of medication (sub optimal prescribing), medication errors, pharmacokinetic and pharmacodynamic changes (changes in the GI absorption, hepatic blood flow reduction, body fat increases, fat soluble drugs undergo slower elimination, impairment of renal function), chronic diseases. ${ }^{3-16}$ Drug related problems are other major issues, and this are directly related with drug utilization among geriatric population. If more number of drugs prescribing to the patient that lead inappropriate prescribing, medication errors, nonadherence, increase morbidity, length of hospitalization, poor quality of life, and finally death may occur. So, to halt such problems regular prescription checking, DOI: 10.5530/ijopp.9.3.8 drug utilization evaluation could be needed, otherwise the geriatrics should face serious consequences regarding the medications. ${ }^{17-20}$ Long term medical care ultimately leads to the inappropriate prescribing, that means failure to providing the quality medical care to the patients and it is achieved by the good clinical practice. To avoid those inappropriate drug use criteria's like Beers and PRISCUS list will be helpful in identifying the potentially inappropriate medications which are prescribed by clinicians. Beers criteria developed by Americans, and they categorized inappropriate medications into three classes, Class1 (potentially inappropriate medication's and classes to be avoided in older adults), class 2 (potentially inappropriate
Address for correspondence: Pradeep Battula, Department of pharmacy practice, Sri Padmavathi School of Pharmacy, Tiruchanoor, Tirupati, A.P, INDIA. Mobile No: +919642423567 Email: doctorbattulapradeep@ gmail.com

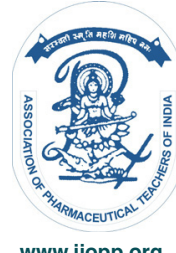

www.ijopp.org 
medication's and classes to avoid in older adults with certain diseases and syndromes that can exacerbated by the drugs), and class 3 (medications to be used with caution). Another tool is PRISCUS list developed in Germany. By using these two tools one can minimize prescribing of potentially inappropriate medications in geriatric patients. In India there are no such tools to identify the PIMs. ${ }^{6,21-24}$ Principally, clinicians do not have evidences of the benefits and risks of the drug therapy, why because older people are excluded from clinical trials due to some barriers include: co-morbidity, cognitive impairment, difficulty in attending for monitoring and finally ethical issues. ${ }^{13}$

The present study was designed to assess the inappropriate use of medications in geriatric patients by Beers criteria and PRISCUS list, drug utilization pattern in geriatric patients, the usage of drugs from WHO essential drug list and National list of essential medicines of India (NLEM), the disease prevalence among this population.

\section{MATERIALS AND METHODS}

A hospital based Prospective observational study was conducted in General Medicine department of Sri Venkateswara Ramnarain Ruia Government General Hospital, Tirupati, India. This study was conducted for a period of six months (January 2015-June 2015). We were collected 140 prescriptions in these six months study, after obtaining the consent from patient. In our study patients of either gender who are above 65 years of age in general medicine in-patient ward with or without co-morbidities were included in the study; we excluded seriously ill patients, patients unable to communicate and Patients unwilling to participate in the study. Study materials include patient data collection proforma, Informed consent form (In vernacular language- Telugu as well as in English), Beers list, PRISCUS list, WHO list, National list of essential medicines of India (NLEM). This prospective study was carried out after approval given by the institutional review board of Sri Padmavathi School of Pharmacy (Permission number SPSP/2014/PB-01). All elderly patients ( $\geq 65$ years) admitted between January to June 2015 in the general medicine in-patient ward of SVRRGGH, was included in the study. A specially designed proforma was used for collecting data which includes patient demographics, past medical history, family and surgical history, co-morbidities, diagnosis and present medications prescribed for each patient. The data was obtained by direct patient interview and from patient case profiles. 140 cases were collected from general medicine wards, according to study criteria. All the prescriptions which contain different drugs were included in the study, all the prescriptions were analyzed for the use of inappropriate medications using American Geriatric Society (AGS) Beers criteria, 2012 and PRISCUS list. Percentage of drug use was calculated according to WHO and NLEM list.

\section{RESULTS}

In a six months study period, a total of 140 cases were collected. All prescriptions are analyzed as per objectives, given in Table 1. Out of 140 cases, $97(69.2 \%)$ were Male and $43(30.71 \%)$ were Female. In total 140 prescriptions, the majority $120(85.71 \%)$ patients were seen between 65-75 years characteristic age group, Followed by age group of 75-85 years were 18 (12.86\%) patients, $>85$ years were $2(1.42 \%)$. Out of 140 cases the highest observed case were cerebrovascular accident (CVA), diabetes mellitus(DM), hypertension (HTN), anaemia and less observed cases were chronic liver disease (CLD), chronic obstructive pulmonary diseases (COPD), are given in Table 2. Co-morbidity means patient is simultaneously suffering from number of diseases, $58(41.4 \%)$ cases as co-morbid, rest of all cases observed as morbid or single disease (58.6\%). Geriatrics posses multiple diseases naturally and for that they need number of drugs, and we were observed 82 (58.57\%) cases as single morbidity, with single co-morbidity $37(26.43 \%)$ cases and with more than single co-morbidity $21(15.00 \%)$ cases (Table 3). Drug utilization pattern concerns, multivitamin were most common prescribed drugs 123 (8.91\%), followed by pantoprazole 122 drugs $(8.84 \%)$. This two were existed in almost all prescriptions, which are given in Table 4, 5 and 6. Out of 1379 medications, highly prescribed formulation was solid dosage forms 571 (41.41\%); that means tablets and capsules, followed by injections 550(39.88\%), nebulizations 48(3.48\%), syrups $35(2.54 \%)$, and others $175(12.69 \%)$ were well prescribed formulations, given in Table 1. Prescribing in generic names was a good thing and easily understandable, 831(60.26\%) generic names were practiced by physicians vastly when compared with brand names 548 (39.74\%), are given in Table 1. In our study, we observe 17 PIMs from beers criteria. The most frequently prescribed PIMs were spironolactone in class 1, followed by Diazepam, Diclofenac and Amiodarone. Only one drug was prescribed in class 2 i.e., Trihexyphenidyl. The Trihexyphenidyl was prescribed to treat the Parkinsonism. But, the patient has urinary tract infection (UTI) as co-morbid. Trihexyphenidyl PIM for the UTIs, it causes urinary retention. From class 3 we observed Carbamazepine, Amitriptyline as PIMs, which are given in Table 7. As well as we observed 10 PIMs according to PRISCUS list, provided in Table 8 . The most frequently prescribed PIMs were 


\section{Table 1: Prescription Analysis}

\begin{tabular}{cc} 
Prescription Catalog & Results \\
\hline Total number of prescription analyzed & 140 \\
Total number of medications prescribed & 1379 \\
Average number of medications per prescription & $9.6(1-10)$ \\
Percentage of medications prescribed by generic name & $831 / 1379(60.26 \%)$ \\
Percentage of medications prescribed by brand name & $548 / 1379(39.74 \%)$ \\
Percentage of medications prescribed by solid dosage form & $571 / 1379(41.41 \%)$ \\
Percentage of medications prescribed by parenterals & $550 / 1379(39.88 \%)$ \\
Percentage of medications prescribed by nebulizations & $48 / 1379(3.48 \%)$ \\
Percentage of medications prescribed by syrups & $35 / 1379(2.54 \%)$ \\
Percentage of medications prescribed by other formulations & $175 / 1379(12.79 \%)$ \\
Medications prescribed from WHO EML & $927 / 1379(67.27 \%)$ \\
Medications prescribed from NLEM India & $1188 / 1379(86.14 \%)$ \\
Prescriptions with polypharmacy & $128 / 140(91.42 \%)$ \\
\hline
\end{tabular}

WHO EML = World health organization essential medicines list

NLEM India = National list of essential medicines of India

Table 2: Prevalent Diseases among Geriatric Patients

\begin{tabular}{cccc} 
S.No & Disease & No. of Patients & Percentage \\
\hline 1. & Cerebrovascular Accident & 24 & $17.1 \%$ \\
2. & Diabetes Mellitus & 10 & $7.1 \%$ \\
3. & Anemia & 13 & $9.3 \%$ \\
4. & Hypertention & 10 & $7.1 \%$ \\
5. & Fever & 10 & $7.1 \%$ \\
6. & Hemiplegia & 7 & $5.0 \%$ \\
7. & Anasarca & 5 & $3.6 \%$ \\
8. & Lower Respiratory Tract Infection & 6 & $4.2 \%$ \\
9. & Chronic Liver Disease & 4 & $2.9 \%$ \\
10. & Chronic Obstructive Pulmonary Disease & 4 & $2.9 \%$ \\
\hline
\end{tabular}

\section{Table 3: List of Patients Simultaneously Suffering with Comorbid IIIness}

\begin{tabular}{cc} 
Number of Diseases patients & Number of Patients \\
\hline 1 & $82(58.57 \%)$ \\
2 & $37(26.42 \%)$ \\
More than 2 & $21(15.00 \%)$ \\
Total & $\mathbf{1 4 0 ( 1 0 0 \% )}$ \\
\hline
\end{tabular}

Nifedipine, Baclofen, Digoxin, Diazepam and Chlordiazepoxide. The commonly observed PIMs from beers and PRICUS list was Nifedipine, Amitriptyline, Chlordiazepoxide, diazepam, among four drugs Diazepam was most frequent which are given in Table 9. Benzodiazepines should avoid in geriatrics, otherwise geriatrics may experience risk of cognitive impairment, delirium, fall, fractures, motor vehicle accidents, slower metabolism.
In total 140 cases, we observed 36 prescriptions as PIPs from Beers criteria, 17 prescriptions as PIPs from PRISCUS list. And both list drugs were present in 14 prescriptions in total observed cases. These PIMs, observed in $39(27.86 \%)$ prescriptions and they identified as potentially inappropriate medications (PIPs) and rest of all 101 prescriptions (72.14\%) free from PIMs. In this six months study period, we observed 74 medications as 
Table 4: Drug Utilization Pattern in Geriatrics

\begin{tabular}{|c|c|c|}
\hline S.No & System & Drugs Prescribed \\
\hline 1 & Cardiovascular Drugs & $\begin{array}{l}\text { Propranolol(5), Nifedipine(2), Amlodipine(38), Atenolol(3), Metoplroplol(3), Digoxin(4), } \\
\text { Amiodarone(30, Enalapril(10), Losartan(1), Telmisartan(1), Atorvastatin(35), } \\
\text { Ivabradine(1). }\end{array}$ \\
\hline 2. & Anti-Infective Drugs & $\begin{array}{c}\text { Amoxicilin+Clavulanic Acid(4), Ceftriaxone(76), Vancomycin(1), Fluconazole(6), } \\
\text { Amphotericin B(1), Metronidazole(23), Itraconazole(1), Ampicillin(3), Amoxicillin(31), } \\
\text { Ciprofloxacin(110, Artisunate(9), Doxycycline(11), Albendazole(8), Acyclovir(1), } \\
\text { Azithromycin(5), Amikacin(1), Tenofovir(1), Ceftaxime(1), Pipericillin+Tazobactam(4), } \\
\text { Diethyl Carbamazepine Citrate(1), Streptomycin(1), Levofloxacin(1), Cotrimoxazole(1), } \\
\text { Norfloxacin(1), Permethrin(1), Framycetin(2). }\end{array}$ \\
\hline 3. & Drugs Acting on GI System & $\begin{array}{c}\text { Pantoprazole(122), Ranitidine(3), Ursodeoxycholic Acid(5), Glycerol(13), Bisacodyl(4), } \\
\text { Ondansetron(22), Sucralfate(1), L-Ornithine(2), Paraffin(1), Lactic Acid(1), } \\
\text { Dicyclomine(2), Magnisium Hydroxide And Aluminium Hydroxide(2), Rifaximin(1), } \\
\text { Racecadotril(1). }\end{array}$ \\
\hline 4. & $\begin{array}{l}\text { Vitamins, Minerals, and Dietary } \\
\text { Supplements }\end{array}$ & $\begin{array}{l}\text { IFA(40), BC(54), Multivitamin(69), Pottasium Chloride(14), Vit.A,C,D(14), Calcium(21), } \\
\text { Methyl Co-Balamine(7), Folic Acid(3), ORS(1), Sodium Bicarbonate(1), } 5 \% \text { And 25\% } \\
\text { Dextrose(16) }\end{array}$ \\
\hline 5. & Analgesic and Anti-Inflammatory & $\begin{array}{l}\text { Paracetamol(76), Aspirin(36), Dexamethasone(4), Prednisolone(3), Tramadol(13), } \\
\text { Diclofenac(3), Piracetam(1), Hydrocortisone(6), Ibuprofen(1), Methadone(1). }\end{array}$ \\
\hline 6. & Drugs Acting on Endocrine & $\begin{array}{l}\text { Plain Insulin(12), Metformin(10), Glimepiride(4), Octreotide(2), Glibenclamide(3), } \\
\text { Levothyroxine(1), }\end{array}$ \\
\hline 7. & $\begin{array}{l}\text { Drugs Acting on Respiratory } \\
\text { System }\end{array}$ & $\begin{array}{c}\text { Salbutamol(35), Budesonide(7), Ipratropium Bromide + Salbutamol(70), Sodium } \\
\text { Chloride (Nasoclear)(1), Cetirizine (9), Montelukast(1), Ethambutol(1), Promethazine(1), } \\
\text { Pheniramine(1). }\end{array}$ \\
\hline 8. & Drugs Acting on CNS & $\begin{array}{c}\text { Gabapentin(2), Levodopa(4), Carbamazepine(3), Phenytoin(4), Diazepam(4), } \\
\text { Hyoscine(2), Clonazepam(1), Donepezil(1), Atropine(2), Chlordiazepoxide(2), } \\
\text { Amitriptyline(1), Baclofen(3). }\end{array}$ \\
\hline 9. & Drugs Acting on Renal System & $\begin{array}{c}\text { Furosemide(51), Spironolactone(10), Mannitol(28), Lactulose(7), Potassium Citrate(2), } \\
\text { Torasemide(1). }\end{array}$ \\
\hline 10. & Drugs Acting on Blood & Clopidogrel(18), Vit.K(5), Pentoxifylline(4),Human Albumin(3), Erythropoietin(4). \\
\hline 11 & Others & $\mathrm{O}_{2}$ Inhalation, DNS, RL, NS, 3\% Nacl, Tranexamic Acid, Cyclosporine, Sorbitrate(146). \\
\hline
\end{tabular}

IFA = Iron Folic Acid

Table 5: Category Wise Distribution of Medications

\begin{tabular}{cccc} 
S.No & System & No. of Medications & Percentage \\
\hline 1. & Vitamins, Minerals, and Dietary Supplements & 240 & $17.4 \%$ \\
2. & Anti-Infective Drugs & 206 & $13.3 \%$ \\
3. & Drugs Acting on Gl System & 183 & $13.3 \%$ \\
4. & Drugs Acting on Respiratory System & 160 & $11.6 \%$ \\
5. & Analgesic and Anti-Inflammatory & 144 & $10.4 \%$ \\
6. & Cardiovascular Drugs & 103 & $7.5 \%$ \\
7. & Drugs Acting on Renal System & 99 & $7.2 \%$ \\
8. & Drugs Acting on Blood & 34 & $2.5 \%$ \\
9. & Drugs Acting on Endocrine & 33 & $2.4 \%$ \\
10. & Drugs Acting on CNS & 28 & $2.0 \%$ \\
11. & Others & 146 & $10.6 \%$ \\
\hline
\end{tabular}




\section{Table 6: Ten Most Frequently Prescribed Medications}

\begin{tabular}{cccc} 
S.No & Medication Name & No. of Prescriptions & Percentage \\
\hline 1. & Multivitamin & 123 & $8.91 \%$ \\
2. & Pantoprazole & 122 & $8.84 \%$ \\
3. & Ceftriaxone & 76 & $5.51 \%$ \\
4. & Paracetamol & 76 & $5.51 \%$ \\
5. & Furosemide & 51 & $3.7 \%$ \\
6. & Iron Folic Acid & 40 & $2.90 \%$ \\
7. & Amlodipine & 38 & $2.75 \%$ \\
8. & Aspirin & 36 & $2.61 \%$ \\
9. & Atorvastatin & 35 & $2.53 \%$ \\
10. & Salbutamol+lpratropium Bromide & 35 & $2.53 \%$ \\
\hline
\end{tabular}

\section{Table 7: PIMs from Beers list}

\begin{tabular}{ccccc}
\hline S.No & PIMs & Class & Medications Frequency & Percentage \\
\hline 1 & Nifedipine & 1 & 2 & $0.15 \%$ \\
2 & Spironolactone & 1 & 9 & $0.65 \%$ \\
3 & Diclofenac & 1 & 3 & $0.22 \%$ \\
4 & Chlordiazepoxide & 1 & 2 & $0.15 \%$ \\
5 & Promethazine & 1 & 1 & $0.07 \%$ \\
6 & Ibuprofen & 1 & 1 & $0.07 \%$ \\
7 & Amiodarone & 1 & 3 & $0.22 \%$ \\
8 & Diazepam & 1 & 4 & $0.29 \%$ \\
9 & Hyoscine & 1 & 2 & $0.15 \%$ \\
10 & Clonazepam & 1 & 1 & $0.07 \%$ \\
11 & Atropine & 1 & 2 & $0.15 \%$ \\
12 & Metoclopramide & 1 & 1 & $0.07 \%$ \\
13 & Dicyclomine & 1 & 2 & $0.15 \%$ \\
14 & Chlorpheniramine & 1 & 1 & $0.07 \%$ \\
15 & Trihexyphenidyl & 2 & 2 & $0.15 \%$ \\
16 & Carbamazepine & 3 & 3 & $0.22 \%$ \\
17 & Amitriptyline & 3 & 1 & $0.07 \%$ \\
\hline
\end{tabular}

PIMs = Potentially inappropriate medications

\section{Table 8: PIMs from PRISCUS list}

\begin{tabular}{cccc} 
S.No & PIMs & Medications Frequency & Percentage \\
\hline 1 & Nifedipine & 2 & $0.15 \%$ \\
2 & Baclofen & 3 & $0.22 \%$ \\
3 & Digoxin & 4 & $0.29 \%$ \\
4 & Pentoxifylline & 1 & $0.07 \%$ \\
5 & Diazepam & 4 & $0.29 \%$ \\
6 & Olanzapine & 1 & $0.07 \%$ \\
7 & Piracetam & 1 & $0.07 \%$ \\
8 & Chlordiazepoxide & 2 & $0.15 \%$ \\
9 & Amitriptyline & 1 & $0.07 \%$ \\
\hline
\end{tabular}




\begin{tabular}{cccc}
\hline \multicolumn{4}{c}{ Table 9: Common PIMs from Beers and PRISCUS list } \\
\hline S.No & PIMs & $\begin{array}{c}\text { Medications } \\
\text { Frequency }\end{array}$ & Percentage \\
\hline 1 & Nifedipine & 2 & $0.15 \%$ \\
2 & Amitriptyline & 1 & $0.07 \%$ \\
3 & Chlordiazepoxide & 2 & $0.15 \%$ \\
4 & Diazepam & 4 & $0.29 \%$ \\
\hline
\end{tabular}

WHO essential medications, most prescribed medications were furosemide, paracetamol, ceftriaxone and salbutamol+ipratropium bromide, from NLEM essential drug list we observed 88 most frequent medications were Furosemide, Pantoprazole, B-Complex and Salbutamol+Ipratropium Bromide. In total of 1379 drugs 34 were not available in both WHO and NLEM essential drug list. We were found 1188 medications (86.14\%)utilized from NLEM was vast and from WHO essential list nearly 927 (67.22\%) medications were utilized to prescribing to the patients.

\section{DISCUSSION}

Prescribing to the geriatrics is challenging, because of their alterations in physiology. Along with that suboptimal prescribing is also major aspect for occurring inappropriateness in prescriptions. Non-adherence, increase morbidity, length of hospitalization, poor quality of life, and finally death may occur as a consequence. In Our study out of the 140 prescriptions 97 were Males, 43 were Females. Patient's age distribution was 120 vast in between $65-75$ years; this was highest when compared with other studies like Lordu et al. and Neha Sharma et al. ${ }^{2,20}$ less when compared with the Venkateswamurthy et al..$^{19}$ Average age of patients was 69.03, it was similar to that of the Ramesh KT et al. ${ }^{18}$ and almost near to the Binit NJ et al. ${ }^{6}$ The average number of drugs per prescription was 9.6, which was similar to Lordu et al. ${ }^{2}$ but when compared with other studies this number was 4 times more. ${ }^{2,6,18-20}$ Among 140 prescriptions 128 $(91.4 \%)$ prescriptions were found as polypharmacy prescriptions, this number was larger than the other studies. Prescription with polypharmacy leads to the ADRs, Drug-Drug interactions, and increased risk of hospitalization, adherence, and medication errors. The total medications prescribed were 1379. Frequently used medications in this study include multivitamins and pantoprazole. But, in other studies mostly prescribed drugs were cardiovascular drugs, drugs acting on the respiratory and NSAIDs, it was different than the other studies. The prescribing of this multivitamins and pantoprazole were frequent prescribing to every patient in hospital. The type of Formulations used were solid dosage forms was $41.4 \%$, parenterals $39.8 \%$; it is almost same to Ramesh Kumar $\mathrm{T}$ et al. ${ }^{18}$ and lesser than the Lordu et al. and Neha Sharma et al. ${ }^{2,20}$ Percentage of medications prescribed with brand names was $39.74 \%$ and the percentage of medications prescribed with generic names was $60.26 \%$, this number was different than other studies. In Lordu et al. ${ }^{2}$ and Neha Sharma et al. ${ }^{20}$ the prescribing of brand names were more than generic prescribing. However, prescribing in generic was good for practice, it avoids conflicts in understanding. The disease pattern in these patients was unlike with other studies. The highest observed case was CVA. In other studies mostly observed cases were cardiovascular diseases and respiratory disorders, but in our study CVA was observed as prevalent disease among admitted patients. Higher PIMs were observed from Beers criteria than the PRISCUS list (17 Vs 10). This was not similar to Binit $\mathrm{NJ}$ et al. ${ }^{6}$ And totally 39 prescription were with PIMs and rest of the prescriptions 101 were free from PIMs. But, in Binit NJ et al. almost all cases had at least one inappropriate medication in their observation. However, like Beers criteria and PRISCUS list, there was no such list in India, so there is need to have a separate list for measuring the inappropriateness in India. A special focus was needed for the geriatric treatment. In this study percentage of medications from the NLEM was $86.14 \%$ and Percentage of medications from the WHO was $67.22 \%$. This numbers were high than the other studies like Lordu et al. and Neha Sharma et al. ${ }^{2,20}$ However,clinical pharmacists as a responsibility should educate and encourage our clinicians to know the importance of prescribing in appropriateness and prescribing from essential drug list, to assure the rational use of medicines in elderly patients.

\section{CONCLUSION}

Inappropriate prescribing in geriatric patients is prevalent. Before prescribing to the patients, evaluation of medications with the suitable criteria is required.

\section{DECLARATIONS}

Ethical approval: Ethical approval given by the institutional review board of Sri Padmavathi School of Pharmacy and Permission number: SPSP/2014/PB-01.

\section{ACKNOWLEDGEMENT}

We would like to thank all the faculty members of General Medicine of SVRRGGH and Department of Pharmacy Practice for their support and kind cooperation to complete this work.

\section{CONFLICT OF INTEREST}


The authors declare no conflict of interest

\section{REFERENCES}

1. Parthasarathi, Nyfort-Hansen, Nahata. A text book of clinical pharmacy practice. 2nd edition. published by universities press Hyderabad. 2013;(4):123-1:3.

2. Lourdu JA, Venkata NKP, Udayalakshmi T, Jayapriya B, Maruti SS, et al. Drug utilization pattern of geriatric patients admitted in the medicine department of a tertiary care hospital. IJPLS. 2013;4(11):3087-92.

3. Mcmillan GJ, HubbardRE. Frailty in older inpatients: what physicians need to know. Q J Med. 2012;105:1059-65. http://dx.doi.org/10.1093/qjmed/hcs125 ; PMid:22753676.

4. Joseph TH, Kenneth ES, Christine MR. Morris Weinberger. suboptimal prescribing in older inpatients and outpatients. Drugs and Pharmacology. 2001;49(2):200-9.

5. Dan Z, Cara T. Educational needs, practice patternsand quality indicators to improvegeriatric pharmacy care. CPJ/RPC 2014;147(2):110-7.

6. Binit NJ, Tejas KP, Manish JB, Chandra BT. Utilization of potentially inappropriate medications in elderly patients in a tertiary care teaching hospital in India. Perspect Clin Res. 2014;5(4):184-9. http://dx.doi.org/10.4103/22293485.140562 ; PMid:25276629 PMCid:PMC4170537.

7. Gallagher P, Barry P, O'Mahony D. Inappropriate prescribing in the elderly. Journal of Clinical Pharmacy and Therapeutics. 2007;32(2):113-21. http:/ dx.doi.org/10.1111/j.1365-2710.2007.00793.x ; PMid:17381661.

8. James CM, lan Hill-Smith, Stephen HDJ. Prescribing for older people. BMJ 2008;336(7644):606-9. http://dx.doi.org/10.1136/bmj.39503.424653.80 PMid:18340075 PMCid:PMC2267940

9. JacsonSHD, MangoniAA., BattyGM. Optimization of drug prescribing. $\mathrm{Br} J$ Clin Pharmacol. 2003;57(3):231-6. http://dx.doi.org/10.1046/j.1365-2125. 2003.02018.x.

10. Jyoti $U$, Yogesh J. Observation of drug utilization pattern and prevalence of diseases in elderly patients through home medication review. Asian Journal of Pharmaceutical and Clinical Research. 2011;57(3):.4(1):143-5.

11. Roger W, Cate Whittlesea. Clinical pharmacy and therapeutics. 5th edition. Churchill Livingstone Elsevier. 2013;149-58.

12. Carol Rancourt, Jocelyne Moisan, Lucie Baillargeon, Rene Verreault, Danielle Laurin, Jean-pierre Gregoire et al. Potentially inappropriate prescriptions for older patients in long-term care. BMC Geriatrics.2004;4(9):1 - 9. http://dx.doi. org/10.1186/1471-2318-4-9.
13. Hilary Anne Wynnea, Julia Blagburnb. Drug treatment in an ageing population: practical implications. Maturitas. 2010;66(3): 246-50. http://dx.doi. org/10.1016/j.maturitas.2010.03.004 ; PMid:20399044.

14. Christopher Beer, Zoe Hyde, Osvaldo P. Almeida, Paul norman, Graeme j. hankey, Bu B. Yeap, Leon Flicker et al. Quality use of medicines and health outcomes among a cohort of community dwelling older men: An Observational Study. BJCP 2010;71(4):592-599.

15. Patrick LM, Stephanie DT, James AL, Jingdong C, Ritesh NK. Prescription drug use among elderly and nonelderly families. Journal of Managed Care Pharmacy.2003;9(1):19-28. http://dx.doi.org/10.18553/jmcp.2003.9.1.19; PMid:14613358.

16. Joseph OF, Segun MA, Olumide AO, Rachel AA. Prescription pattern and prevalence of potentially inappropriate medications among elderly patients in a Nigerian rural tertiary hospital. Therapeutics and clinical risk management. Dovepress. 2013;6:115-20.

17. Joseph TH, Kenneth ES, Todd PS. Update of studies on drug-related problems in older adults. J Am Geriatr Soc. 2013;61(8):1-6.

18. Ramesh KT, Shahina S, Shobha JC, Naidu MUR, Usha Rani P, Vijay T,et al. Drug utilization in geriatrics population in a Tertiary care centre. JK Science. 1999;1(3):118-120.

19. VenkateswaramurthyN, Hafis Muhammed PM, Sambathkumar.R. Drug utilization pattern among geriatric patients in a tertiary care teaching hospital. AJPHR. 2014;2(12):211-218.

20. Neha S, Uma A, Shobha K, Rahul P, Alka B, Rajeev RS, et al. Screening of prescriptions in geriatric population in a tertiary care teaching hospital in north India. JPHYTO. 2013;2(5):38-45.

21. Christine MC. American geriatrics society updated beers criteria for Potentially inappropriate medication use in older adults: the American geriatrics society 2012 beers criteria update expert panel the American geriatrics society, New York, New York published In Final Edited Form As: J Am Geriatr Soc. 2012;60(4):616-31.

22. Stefanie Holt, Sven Schmiedl, Petra A. Thurmann. Potentially inappropriate medications in the elderly: The PRISCUS List. Dtsch Arztebl Int.2010;107(31-32): 543-51. PMid:20827352 PMCid:PMC2933536.

23. Daniela f, Graziano onder. Medication errors in elderly people: contributing factors and future perspectives. BJCP. 67(6): 641-645.

24. Mark M, Dipika MM, Becky AN, Miriam AK. Improving prescribing patterns for the elderly through an online drug utilization review intervention a system linking the physician, pharmacist, and computer. JAMA.1998;280(14):1249-52. http://dx.doi.org/10.1001/jama.280.14.1249 . 